ERRATUM

\title{
Molecular and biogeochemical evidence for ammonia oxidation by marine Crenarchaeota in the Gulf of California
}

\author{
J Michael Beman, Brian N Popp and Christopher A Francis
}

The ISME Journal (2008) 2, 453; doi:10.1038/ismej.2008.33

Correction to: The ISME Journal (2008) 2, 429-441.

Owing to a publishing error, Figure 2 in the above paper was reproduced incorrectly when published online and in this issue. The correct Figure 2 is shown below.

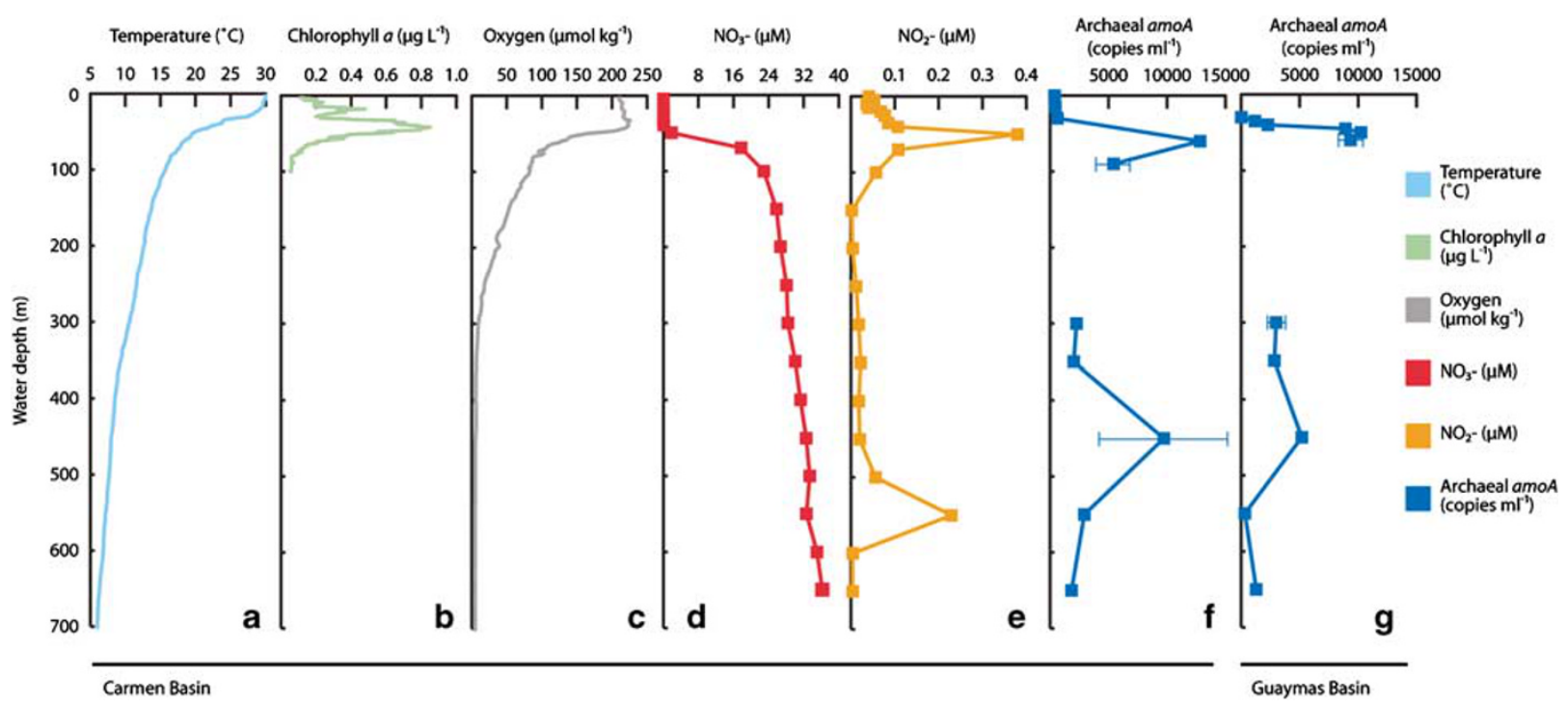

Figure 2 Profiles from 0 to $700 \mathrm{~m}$ of temperature (a), chlorophyll $a(\mathbf{b})$, dissolved oxygen (c), $\mathrm{NO}_{3}^{-}(\mathbf{d})$ and $\mathrm{NO}_{2}^{-}(\mathbf{e})$ in the Carmen $\mathrm{Basin}$, and $a m o A$ gene copies from the Carmen (f) and Guaymas Basins (g). Data from 0 to $100 \mathrm{~m}$ are from the group A archaeal $a m o A$ assay and $300-650 \mathrm{~m}$ from the general assay. Error bars denote one standard error of the triplicate quantitative PCR (qPCR) measurement and are not visible when less than the width of the data point. 